\title{
AN EXPECTATIONAL VIEW OF CONSUMER SPENDING PROSPECTS
}

\author{
F. Thomas JUSTER * \\ University of Michigan, USA
}

Received December 1980; accepted February 1981

While the path of the economy clearly depends on a lot more than the behavior of consumers, the latter is surely one of the key influences on the former. After all, consumer spending counts for about two-thirds of the total (more if consumer investments in owner-occupied housing are included), and postwar business cycle movements in the U.S. have typically been foreshadowed by significant changes in consumer spending, particularly for automobiles and houses. Thus, whether the economy will be proceeding along at reasonably satisfactory growth rates, sliding into recession, or accelerating into renewed expansion will be heavily influenced by what consumers do.

\section{Theory}

Consumer spending decisions are influenced by three sets of factors: changes in real income growth rates, changes in balance sheet position, and changes in "animal spirits", or more prosaically, in consumer expectations, attitudes and plans. Most models of consumer behavior focus heavily on income and balance sheet variables, with particular attention typically paid to changes in transitory and permanent income and income taxes, and to net worth. Recent work has also focused on the asset and liability sides of the balance sheet, on the grounds that liquidity differences are important. Some few models attempt to introduce expectational measures into the econometrics, but such variables typically carry little weight in the models.

The behavior of the variables in these models is especially interesting when viewed over the late 1970s, when the expansion beginning in 1975 was beginning to show signs of weakening. During 1978, most of the

* Author's address: F. Thomas Juster, Institute for Social Research, University of Michigan, P.O. Box 1248, Ann Arbor, MI 48106, USA. 
financial variables that tend to enter consumption equations were behaving in ways broadly consistent with sluggish to modest growth in consumption. Over this period, for example, real disposable income had grown at roughly a four percent growth rate, both consumer installment debt and mortgage debt had increased substantially, and prices were rising at roughly a seven percent rate.

The debt changes were particularly noteworthy. Since the middle of 1977 there had been a veritable explosion in outstanding mortgage debt, apparently reflecting some monetization of the rapidly rising housing equity among American consumers resulting from fast growing housing prices. In the first part of 1977, for example, mortgage debt was rising at an annual rate of about $\$ 70$ billion, but in the last half of 1977 mortgage debt increments averaged about $\$ 100$ billion. The pace slackened off a bit during the first half of 1978, but was still quite high. On consumer installment debt, 1976 saw changes running at about $\$ 20$ billion annual rates, 1977 saw the changes running over $\$ 30$ billion, and in later 1978 the data showed changes of $\$ 40$ billion. To a substantially greater extent than usual, the strength in consumption spending during this expansion was supported from debt extensions.

The late 1970s data on consumer expectations and attitudes were a little schizophrenic, although on the whole clearly pessimistic. Overall, the Michigan Index of Consumer Sentiment reached a peak of 89.1 in the May 1977 survey. Since then, it had gone erratically downhill; the reading was 82.4 in July 1978 , but the low up to that point had actually been reached in March of 1978, at a level of 78.8.

This overall downward sag masked two sharply divergent movements in components on the Consumer Sentiment Index. Several measures are best thought of as reflecting current buying conditions, and these had hardly declined at all from the peaks reached late in 1977. In July, 1978, for example, the two Current Conditions components were only a couple of index points below their recovery highs. In sharp contrast, a component best labeled an expectations component had declined quite sharply from peaks reached in 1977: two of the expectations measures had declined by about 30 index points, the other by about 15 points. Thus expectations have been declining more or less steadily since the middle of 1977, while current buying conditions had help up quite strongly.

The key to this schizophrenia clearly lay in consumer perceptions of and reactions to price increases, and in perceptions about the ability of 
economic policy to cope with inflation. The pervasive consumer reaction to general price increases during the postwar period had always (with few exceptions) been retrenchment on spending and increases in saving. But reactions to prospective price increases for specific items like houses and cars can be, and in 1978 was, quite different. The survey data are unambiguous on this point: many consumers though that this was a good time to buy houses and cars, mainly because they expected housing and car prices to rise substantially in future, and hence felt that it was better to buy now rather than wait until later. Thus anticipatory buying was clearly an important element in consumer behavior, and had been holding up the rate of consumer spending in the face of increasing pessimism about both short- and long-term economic prospects. And consumer skepticism about the ability of policy-makers to cope with macro-economic problems underlay their pessimism about general economic prospects.

The key role played by price expectations and judgements about the effectiveness of economic policy is shown in tables 1 and 2. Table 1 tabulates changes in the reasons why consumers expected business conditions to be good or bad over the next 12 months or over the next five years. Two factors stand out: first, consumers were increasingly less likely to regard effective government economic policies as a reason to expect good business conditions; second, consumers were increasingly more likely to link unfavorable expectations about future business conditions to expectations of increased prices. Thus the decline in optimism about both short- and long-term business conditions was in some significant part due to the expectations that inflation will bring on deteriorating business conditions, and to the expectation that economic policy would fail to cope with deteriorating business conditions [1].

Table 2 addresses the buy-in-advance motivations noted above in the text. Here, the proportion of respondents who judge that the present is a good time to buy household durables, houses and cars had risen sharply over several years prior to 1978 , and had held up strongly in 1978 largely because an increasing proportion of people report that this was a good time to buy because prices would be higher in future. As a proportion of all favorable opinions about why "this is a good time to

[1] These data do not reveal whether judgments about the ineffectiveness of economic policy were due to the perception that policy-makers were less adept now than formerly, or to the perception that the problems, were more intractable than they used to be. 
buy", the anticipatory buying rationale has almost doubled for household durables since 1975 and had exactly doubled for automobiles.

In a general sense, it can be argued that all of the consumer survey data were signalling prospective weakness. Increasing pessimism based on deteriorating expectations clearly foreshadows future weakness in spending, and while anticipatory buying is a reflection of current strength, it is surely a harbinger of future weakness. At some point, consumers would decide that the risks of deteriorating financial position no longer warranted buying in advance of expected price increases for specific products, and anticipatory buying would come to a halt. When that happened, consumer spending would be expected to be weaker than if such advance buying had not taken place to begin with, and there existed the potential for a significant slide in consumer spending.

\section{Modelling consumption behavior [2]}

Both the real economic variables that influence consumer behavior and the anticipatory ones can be combined into a set of forecasting models which can be used to view the likely path of future consumption. It is an article of faith with most economists that if consumer expectations, attitudes and plans are important, they ought to show up in conventional econometric models as significant independence forces on consumer behavior. One can of course quarrel with that article of faith: the alternative argument essentially says that econometric models are doomed to failure because the real world is structurally unstable, hence capturing the influence of the past on the present will lead to major errors in predicting the future because new and important factor(s) will come along to upset the model.

The resolution of methodological issues like this presumably lies in empirical testing. The set of models presented here have been used in consumption forecast for the last several years, and represent an attempt to combine traditional economic variables with expectational measures in a set of single equation demand models. The models do not comprise a complete forecasting system, since they contain a number of variables that would normally be endogenous to such a system. All the

[2] The analysis here draws heavily on other work done by the author. 
Table 1

Proportion of respondents giving indicated reason for expectations about business conditions.

\begin{tabular}{ccccccc}
\hline & $\begin{array}{c}\text { Feb. } \\
1977\end{array}$ & $\begin{array}{l}\text { May } \\
1977\end{array}$ & $\begin{array}{l}\text { Aug. } \\
1977\end{array}$ & $\begin{array}{l}\text { Nov. } \\
1977\end{array}$ & $\begin{array}{c}\text { Feb. } \\
1978\end{array}$ & $\begin{array}{c}\text { May } \\
1978\end{array}$ \\
\hline $\begin{array}{c}\text { For the next 12 months } \\
\text { Optimistic expectations due } \\
\text { to favorable references } \\
\text { to government economic } \\
\text { policies }\end{array}$ & $24 \%$ & $14 \%$ & $11 \%$ & $7 \%$ & $6 \%$ & $5 \%$ \\
$\begin{array}{c}\text { Pessimistic expectations due } \\
\text { to unfavorable references } \\
\text { to expected price increases }\end{array}$ & 6 & 12 & 12 & 13 & 11 & 21 \\
$\begin{array}{c}\text { For the next five years } \\
\text { Optimistic expectations due } \\
\text { to favorable references } \\
\text { to government economic } \\
\text { policies }\end{array}$ & 23 & 18 & 14 & 11 & 10 & 8 \\
$\begin{array}{c}\text { Pessimistic expectations due } \\
\text { to unfavorable references } \\
\text { to expected price increases }\end{array}$ & 7 & 14 & 12 & 14 & 12 & 21 \\
\hline
\end{tabular}

Table 2

Proportion of respondents giving favorable market evaluations and buy-in-advance price rationales.

\begin{tabular}{|c|c|c|c|c|c|}
\hline & $\begin{array}{l}\text { May } \\
1975\end{array}$ & $\begin{array}{l}\text { May } \\
1976\end{array}$ & $\begin{array}{l}\text { May } \\
1977\end{array}$ & $\begin{array}{l}\text { May } \\
1978\end{array}$ & $\begin{array}{l}\text { June } \\
1978\end{array}$ \\
\hline \multicolumn{6}{|l|}{ Household durables } \\
\hline \multicolumn{6}{|l|}{ Percent saying } \\
\hline Good time to buy & $37 \%$ & $42 \%$ & $62 \%$ & $63 \%$ & $66 \%$ \\
\hline $\begin{array}{l}\text { Good because prices will } \\
\text { go higher }\end{array}$ & 15 & 22 & 37 & 31 & 48 \\
\hline $\begin{array}{l}\text { Buy-in-advance reasons as } \\
\text { a proportion of all } \\
\text { favorable opinions }\end{array}$ & 0.41 & 0.52 & 0.60 & 0.49 & 0.73 \\
\hline \multicolumn{6}{|l|}{ Cars } \\
\hline \multicolumn{6}{|l|}{ Percent saying } \\
\hline Good time to buy & 30 & 37 & 48 & 50 & 53 \\
\hline $\begin{array}{l}\text { Good because prices will } \\
\text { go higher }\end{array}$ & 11 & 19 & 27 & 33 & 39 \\
\hline $\begin{array}{l}\text { Buy-in-advance reasons as } \\
\text { a proportion of all } \\
\text { favorable opinions }\end{array}$ & 0.37 & 0.51 & 0.56 & 0.66 & 0.74 \\
\hline
\end{tabular}


models contain one or more variables reflecting consumer anticipations, and they are consciously designed to allow such variables to play an important role in explaining behavior. Some of the models are dominated by the expectational variables, and conventional variables play only minor roles; others are dominated by conventional variables and the expectational variables play relatively minor roles. All have well developed theoretical and empirical foundations. The models include an equation predicting the personal saving rate, an equation predicting unit sales of automobiles, and an equation predicting the average "real price" of automobiles.

\section{Saving rate}

The saving rate model is essentially the same as the one presented in Juster and Taylor (1975), and essentially blends the Houthakker-Taylor zero-depreciation model of saving behavior with the short-run uncertaintly influences analyzed in the series of papers by Juster and various colleagues (Juster 1973, 1975; Juster and Wachtel 1972). The theory is relatively straightforward. In the long run, assuming no growth in income or in population, saving would disappears as assets become adjusted to the steady-state long-run income level. Thus saving arises because of disequilibrium between assets and income, or out of population growth. In the short run, changes in various components of income (including personal taxes and social security taxes) will produce positive or negative saving as part of the adjustment process. Finally, uncertainty about real income prospects will have an impact on shortrun saving behavior, although uncertainty factors are expected to have little or no long-run effect.

In previous work, the author along with a number of colleagues has used consumer expectations about price changes as a proxy for real income uncertainty. The best proxy in most previous work has proved to be the variation in expected price change among households, rather than the mean level of price change expected by households. The argument is that wide variation among households in the mean expected price change will tend to be associated with greater uncertainty at the level of individual expected price change, and it is individual uncertainty about price changes expected in the future which is the principal cause of real income uncertainty. 
The automobile demand equations differentiate the demand for unit sales and the demand for "quality" per unit. Unit sales are explained within a stock adjustment framework, but the dynamics of the process are subsumed within a measure of automobile purchase probability obtained from the surveys. The transitory effects of income change and expectations on automobile sales are reflected by another survey measure of optimism/pessimism, and by real income change and the rate of unemployment. The unit sales equation has several dummy variables reflecting special factors in the automobile market-strikes, rebates, and inventory cleanup prior to the introduction of new models.

Automobile "real price" or quality is basically explained by the level of real per-family income. In some equations estimated in the past, the level of auto unit sales had been found to impact on average quality, the presumption being that the distribution of automobile buyers is different in boom auto quarters than in average or slack quarters. During boom quarters, e.g., relatively low income families are more apt to be in the car buying market, and the average quality of the vehicles they purchase is apt to be lower. But that variable proved not to be important in the version of the model presented here. In these equations, automobile unit sales are dominantly explained by expectational variables reflecting cyclical swings in income and optimism, while automobile real price (quality) is dominantly explained by the level of income.

\section{Empirical estimates}

The basic empirical estimates for the personal saving rate are shown in table 3, while estimates for the automobile purchase rate and the average real price of automobiles are shown in table 4.

In the top panel of table 3 , the first equation shows the basic Houthakker-Taylor saving rate equation. The remainder of the rows show the results of estimating equations which add alternative measures of the uncertainty effect to the basic model. Equation 2 adds the filtered [3] changes in the Index of Consumer Sentiment (ICS), while the other equations add both the filtered ICS and a set of lagged

[3] The filter eliminates changes in the ICS which are neither large nor systematic. The methodology is explained in Juster and Wachtel 1972. 


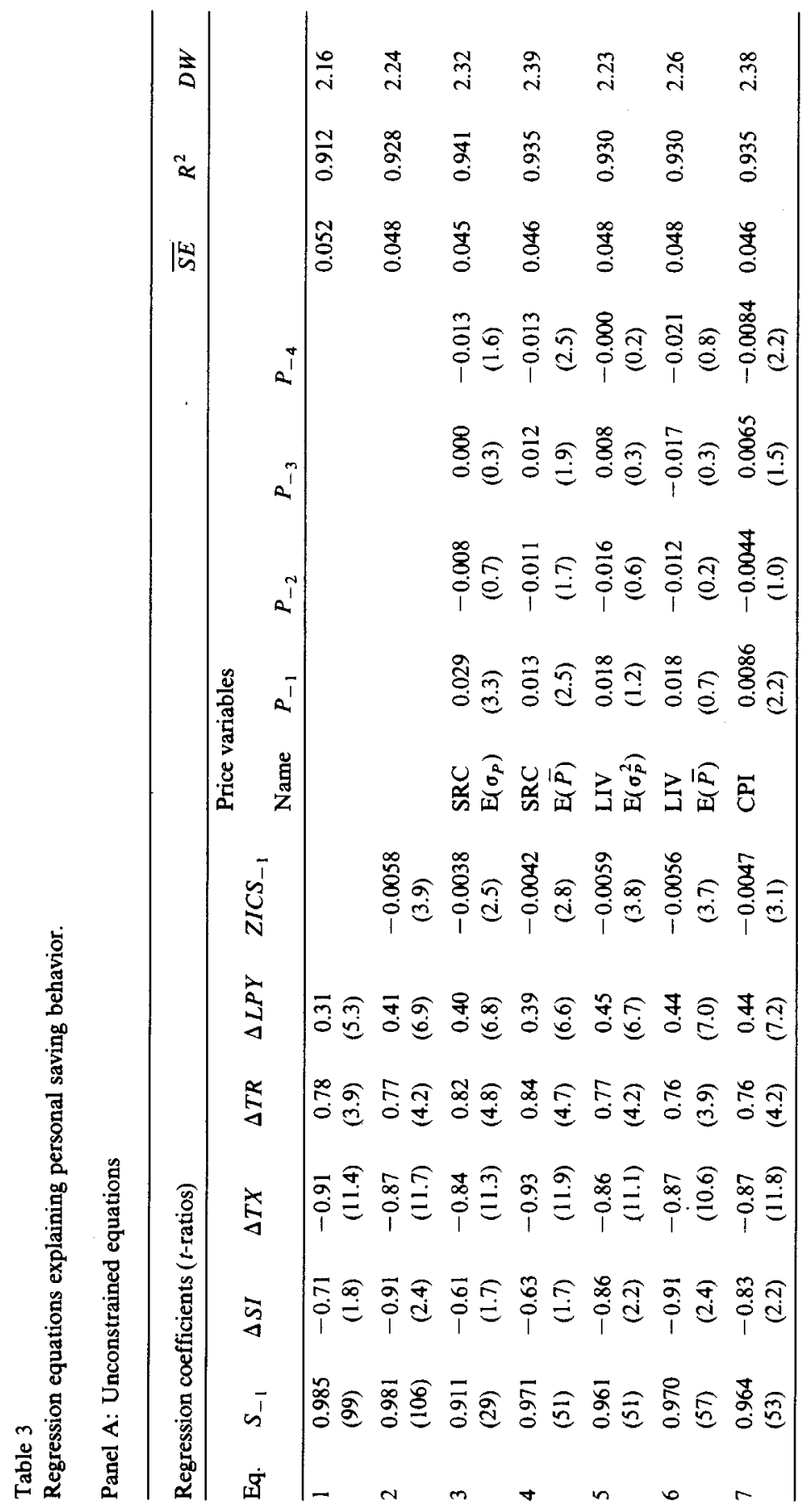




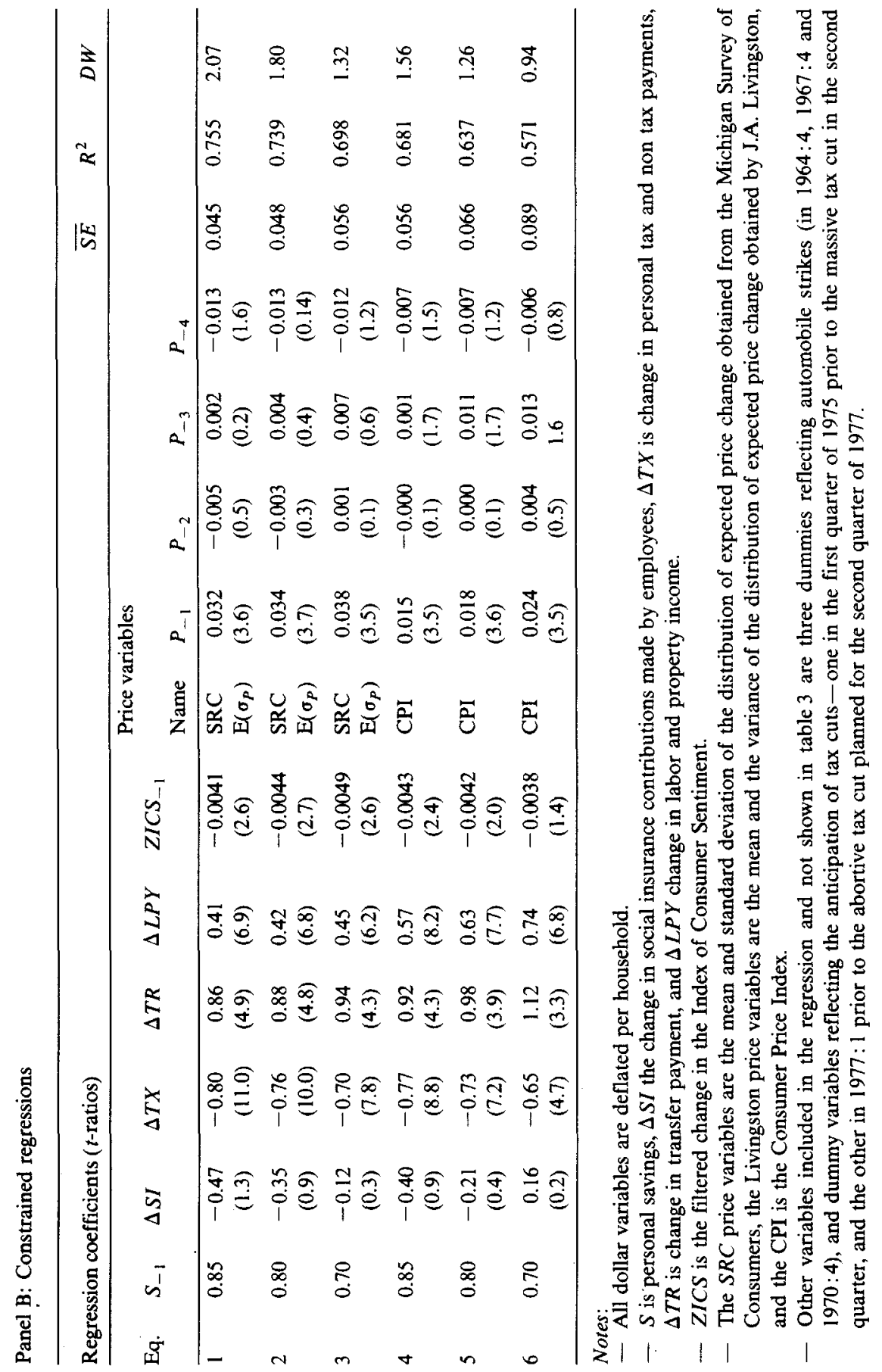


variables reflecting either prices or some dimension of expected price change. The price measures presented here include actual price change as measured by the Consumer Price Index, both the mean and the standard deviation of the Michigan data on price changes expected by consumers, and both the mean and the variance of price changes expected by the panel of professional economic forecasters surveyed by the financial columnist, J.A. Livingston.

In the bottom panel of table 3 , a number of constrained regressions are shown. All the data in the top half of the table imply very long lags in the response of consumer saving to changes in income components or in uncertainty. These lags seem unreasonably long on a priori grounds, and the bottom half of the table constraints the coefficient of the leg term to imply a quicker response of saving to changes in income or uncertainty.

Several features of these results are worth noting in detail. First, while the basic Houthakker-Taylor model produces reasonably good fits to the data, the addition of the uncertainty measures cuts the residual unexplained variance significantly - by about 20 percent, for the best of the equations involving uncertainty variables. Next, while the survey measures of expected price changes are slightly superior to the Consumer Price Index in unconstrained equations, the expectations do quite a bit better in the constrained regressions in the lower part of the table. If the constrained regressions convey a more accurate picture of the true lag structure in the model, the data suggests that expectations about price change contain significant information not contained in actual price change, although the actual change is not a bad proxy for price expectations. Of the two expectational measures from the Michigan data, the standard deviation of the expected price change data is a shade better than the mean expected rice change, although the margin of superiority is trivial.

One of the most interesting results in the table is the relatively poor performance of the Livingston data on the price expectations held by professional economic forecasters, relatively to the price expectations held by consumers. The Livingston data have been used in a number of studies concerned with the structure of price expectations, partly because they have been widely available and partly because they have a very long history going back to the late 1940s [4]. In addition, some

[4] See John A. Carlson 1977; and Mullineaux 1978. 
would argue on theoretical grounds that the Livingston series is the right data to include in models of consumer or business decision making.

The last point is of some methodological as well as practical interest. One school of though with substantial influence in many current policy discussions takes the view that decisions are made on the basis of "rational" expectations, by which is meant simply that decision makers act on the basis of the best available information including forecasts of the probable impact of economic activity on policy-making. In a world with zero information dissemination costs, the professional efforts of economic forecasters are presumably worth more weight than the unguided guesses of a representative sample of consumers. But there is no evidence from table 3 that consumers act in that way: their personal saving behavior is not at all well explained by the guesses of professional forecasters, which ought to be the proper ingredient in a rational expectations world. Rather, they act on the basis of their own expectations, which differ significantly and often vary sharply from the expectations of professional forecasters. Thus, however relevant the rational expectations model may be for commodity markets and other market in which professional speculative activity is a dominant force, that seems not to be true of the formation of consumer expectations about price change nor of the behavior relationship between price expectations and savings. I find those results both plausible and sensible - and enlightening about the appropriate role of the rational expectations theory in economic modeling and in the formulation of economic policy.

Comparison of the SRC data on expected price change and actual price change are interesting and potentially illuminating. In the top half of the table, as noted above, there is virtually no difference in the fit of expected price change (either standard deviation or mean) and actual price change: both convey the same impression about the effect of price changes on consumer saving behavior, in that they suggest that a rise in either actual prices or expected prices (means or standard deviations) will result in higher saving. But if the lag structure estimated in the model is wrong, in that the response of saving to changes in income components or uncertainty is more rapid that that implied by the point estimates, then the data in the bottom half of the table become more relevant. Here, while both equations necessarily deteriorate somewhat in fit, the equation with actual price change deteriorates much more rapidly. 
One explanation for the roughly equivalent impact of actual or expected price changes on savings in the top half of the table is that the unconstrained equation essentially fits a very long moving average of all the independent variables to actual savings. If the moving average is long enough, there can hardly be much difference between the explanatory power of expected price changes and actual price changes, provided the two bear a reasonably close resemblance to each other, as of course they do. But in the constrained regressions in the bottom half of the table, one would expect to find greater discriminating power, and that comparison clearly favors the role of expected price change in determining saving behavior.

Other tests with the saving model shown in table 3 were also conducted, primarily to see if the very large coefficients of personal tax change, social security tax change, and change in transfer payments could be due to the presence of poorly measured seasonal variation. The presence of a poor seasonal adjustment for series used in an equation consisting of seasonally adjusted variables would be shown by significant regression coefficients attached to seasonal dummy variables inserted in the equation. But neither straightforward seasonal dummies themselves, nor seasonal dummies interacted with particular tax or transfer items, proved to be of any use in the equation. In no case was the $t$ ratio for either the dummies or the dummies interacted with the tax/transfer items more than about 1.5, and in the preferred equation, all $t$ ratios were less than one. Hence, whatever is accounting for these very strong impacts of tax and transfer changes on saving, it appears not to be poor seasonal adjustment of the series themselves.

The basic saving rate equation does contain a set of dummy variables not shown in table 3, which are included to adjust for the effects of particular events that the equation should not be expected to reflect. Specifically, dummy variables are included for the three automobile strike quarters - the fourth quarters of 1964, 1967, and 1970. Automobile strikes are associated with low levels of automobile sales, and since automobile sales are an extremely important determinant of change in consumer installment credit, they also have a significant impact on the measured personal saving rate. All these dummies had $t$-ratios in excess of 1.7, with the 1964 strike dummy being about three times its standard error. In addition, there is some indirect survey evidence to suggest that the 1975 cut in personal income taxes had an effect on personal saving prior to its implementation, and similar (but less persuasive) evidence 
that the abortive 1977 second quarter tax cut also had an anticipatory impact on saving behavior. Thus the equation has first quarter 1975 and first quarter 1977 dummy variables, designed to reflect anticipation of a tax cut.

\section{Automobile sales}

The automobile purchase rate model in the paper is very similar to one that has been used for some time by the author, and reported in a number of papers [5]. The model implies a stock adjustment framework, with transitory changes in income having a strong effect on automobile sales. For the empirical implementation, a good bit of evidence suggests that a survey measure of automobile purchase probability is a good substitute for the entire stock adjustment process, while other survey measures of optimism tend to be superior to objective measures of income change. The idea is that consumers reported probability of vehicle purchase must reflect the mechanism implied by a stock adjustment process, and hence can replace that part of the model.

The equations summarized in table 4 are basically driven by the two survey measures of vehicle purchase probability and the Index of Consumer Sentiment, but the present version of the model provides room for a couple of conventional financial variables - the change in real per-household income, and the general unemployment rate. The equation also has a number of dummy variables that are not shown in the table: three automobile strike quarters are treated with dummy variables $(1964: 4,1967: 4$ and 1970:4), there is a dummy variable for the extensive automobile rebates in the first quarter of 1975, and there is a dummy reflecting the relatively high sales associated with model cleanup, assigned to the third quarter of each year. All these dummies are statistically significant except for the 1967:4 strike dummy, which is marginally significant at conventional levels.

One interesting aspect of the model fitted through the first quarter of 1978 is the reemergence of financial variables as having some independent influence on purchase rates. In the version estimated through 1974, neither level of real per household income, change in income, nor

[5] For example, Juster and Wachtel 1972. 


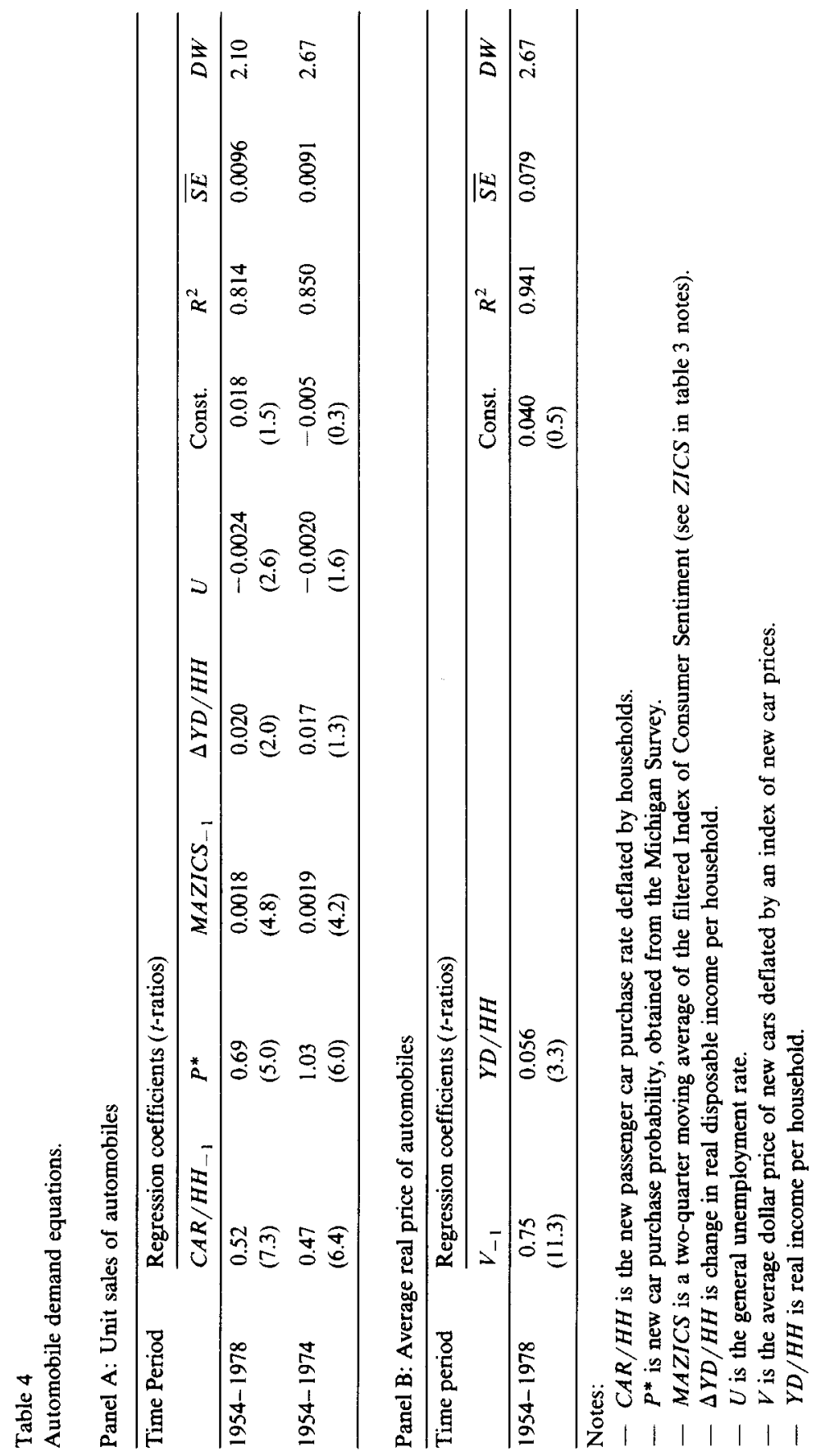


the unemployment rate made significant contributions to an explanation of purchase rates. But in equations fitted through 1978, both real income change and unemployment become significant at conventional levels, while the estimated influence of the survey variables is a bit less.

A possible interpretation of this shift of power in the equation from expectational to real financial variables is that the uncertainty which has characterized the economy during recent years has meant that consumers are more apt to behave in accordance with actual events than with events that they anticipate, because the anticipations themselves are less firmly held and therefore less closely linked to actual behavior. Given the notorious sensitivity of time series to minor shifts in data occasioned by revisions, as well as to the presence or absence of other variables, that must be regarded as speculative. But it seems an interesting speculation, and is in accord with what does seem clearly the case-that consumers are much more volatile in their expectations and attitudes now than they were back in the 1960s and early 1970s, and the increased volatility could mean that the link between expectations and behavior has become modified.

The equation explaining real car price (average quality per car) is straightforward. Average car quality appears to be a simple function of permanent income, and is reflected by an equation with real per-family income and a distributed lag. The equation is also shown in table 4.

\section{Using models to forecast}

One can use the set of models described above to make predictions of the saving rate, the level of automobile sales, the level of real automobile price (i.e., quality), and automobile demand in constant dollars, provided estimates of the relevant independent variables, such as changes in real income components and the future values of the survey measures, can be obtained. Inserting plausible values of the independent variables into these models would have yielded 1979 predictions of an increase in the rate of personal saving, and a decline in the automobile sales rate. The second of these events would have been accurately foreshadowed, but the first would not - the rate of personal saving continued to drop throughout 1979 , and reached historically low levels during the latter part of that year.

It is instructive to ask: why would the saving rate model have 
produced estimates that were wide of the mark during 1979? The answer lies in the analysis described earlier in the text, where the growing divergence between the current conditions and expectations components on the index of the consumer sentiment were discussed. While it was clear enough that expectations were getting more pessimistic, and while they actually became more pessimistic during 1979, it was also true that speculative buying, which is reflected by the survey measures of current market conditions, grew in strength. But the role of price expectation in the above model is to measure uncertainty about future changes in real income, and the model contains no provision for the role of anticipatory buying in the determination of saving behavior. Thus during a period when anticipatory buying forces reached record levels in the U.S. economy, a model which behaved quite sensibly during most of the postwar period would have provided estimates of saving behavior that turned out to be quite far off the mark.

The basic message from this exercise is that one has to be very chary in using time-series models that may reflect shifting relationships. Implicitly, the models discussed in this paper could be expected to hold in economic environments where the dominant reaction of consumers to expectations in rising prices is the conservatism and caution induced by the uncertainty associated with changes in future real income. While that was true throughout virtually all of the postwar period in the U.S., it was clearly not true of developments in 1978 and 1979, where the dominant reaction to the expectation of rising prices was speculative buying and debt acquisition centered in housing, cars, and durables.

We may ask: why did U.S. consumers react with a speculative buying response to the inflation of 1978-79, while they failed to react in that way to the inflation of 1973-74? The likely answer is that consumers learned from experience. In 1973-74, when the first bout of double-digit inflation associated with rising oil and other raw material prices was experienced in the U.S. and the western world generally, consumers reacted with the view that those volatile price rises would not be associated with gains in money income, hence would be reflected in sharply declining real incomes. While real income did in fact decline as a consequence of a severe recession, consumers discovered that they survived the crisis and that neither their financial status nor the economy fell apart in the face of inflationary stresses. Thus, when the next episode of double-digit inflation began to appear in the late 1970s, they were more impressed by the gains to be obtained from acquiring 
goods via expanded debt than by the prospective losses resulting from the uncertainties associated with an overextended financial position. And the proposition that consumer spending would collapse when the speculative buying fever finally burst was strikingly demonstrated during the early spring of 1980 , when the speculative buying measures collapsed, and with them consumer spending, in the aftermath of the vigorous anti-inflation and credit control measures announced by the Federal Reserve Board and the President in March of that year.

\section{References}

Carlson, John A., 1977. A study of price forecasts. Annals of Economic and Social Measurement 6 (Winter), 27-56.

Juster, F. Thomas, 1973. Savings behavior, uncertainty and price expectations. The economic outlook for 1974. Papers presented to the 21st Conference on the Economic Outlook at the University of Michigan, Nov., 1973.

Juster, F. Thomas, 1975. Inflation and consumer savings behavior-some time-series and crosssection results. Prepared for the CIRET conference, Stockholm, Sweden, June 1975 (mimeo).

Juster, F. Thomas and Lester Taylor, 1975. Toward a theory of saving behavior. Papers and Proceedings of the American Economic Association, May, 1975.

Juster, F. Thomas and Paul Wachtel, 1972. A note on price inflation and the savings rate. Brookings Papers on Economic Activity 3, 765-778.

Mullineaux, Donald, J., 1978. On testing for rationality: another look at the Livingston price expectations data. Journal of Political Economy 86, 329-335. 